\title{
VAD ÄR EN FRAMGÅNGSRIK BROTTSOFFERPOLITIK?
}

\section{Av PROFESSOR HeNRIK THAM}

Ideally, a policy that strengthens the position of crime victims should not infringe on the rights of suspects or sentenced persons. There are obvious tensions in this regard in the new policy that must be discussed. Such tensions exist, for example, when the state sides with victims in the name of human rights, yet thereby risks violating traditional human rights for citizens, especially if the restoration of the victim is said to require the punishment of the perpetrator, or if the creation of an ideal victim demands the creation of a stereotyped perpetrator. In order to develop a successful crime victim policy, it is important to base that policy on research and experience, to recognize that there are different sorts of victims with differing needs, and to avoid being influenced by ideologies and preconceptions. ${ }^{*}$

Aina Mee Ertzeid har skrivit informativt om brottsoffers ställning i brottmål i Norge och i Norden. Hennes utgångspunkt är juristens, min är kriminologens och samhällsvetarens. Ur mitt perspektiv ska jag kort kommentera likheter och skillnader mellan de nordiska länderna, några för- och nackdelar med att stärka brottsoffrets ställning, och frågan om vad som är en framgångsrik brottsofferpolitik. Jag kommer att vidga frågan något från brottsoffrets ställning i brottsmålsprocessen till brottsoffret i rättsväsendet och politiken också i övrigt.

\section{Nyklassicismen}

Brottsoffret har sedan flera decennier fått en successivt starkare ställning i de flesta västländer. Det gäller även de nordiska länderna. Aina Mee Ertzeid framhåller dock intressant att de nordiska länderna valt delvis ganska olika sätt för att stärka brottsoffret. Hon talar om en östnordisk och en västnordisk modell, där Finland och Sverige representerar den förra och Danmark, Island och Norge den senare. De östnordiska länderna förefaller här ligga före på brottofferpolitikens område, och särskilt Sverige har strävat efter att spela en ledande roll.

Ett bidragande skäl till skillnaden mellan länderna kan vara att Sverige och Finland starkare kom att präglas av nyklassicismen än de andra länderna (Christie 1980, Stenborre 2003). Från 1970-talet gled straffteorierna från relativa till absoluta teorier. En mer pragmatisk och instrumentell hållning byttes mot en som betonade straffvärde och proportionalitet i straffmätningen. Kriminalpolitikens fokus

\footnotetext{
* Title in English: What is a Successful Crime Victim Policy. Original in Swedish.
} 
flyttades samtidigt från gärningsman till offer. I den nya diskursen var det inte längre gärningsmannens behov av vård som stod i centrum, utan offret som led skada på grund av ett avsiktligt övergrepp. Gärningsmannens uppsåt blev en förutsättning för konstitueringen av offret, och offret skulle upprättas genom gärningsmannens bestraffning, som en tidigare svensk justitieminister uttryckt det (Justitiedepartementet 1993). Nyklassicismen förefaller alltså ha underlättat brottsofferdiskursen som blivit starkare i de "mer nyklassiska" östnordiska länderna. ${ }^{1}$

\section{Kränkning i Danmark och Sverige}

En annan skillnad mellan ett östnordiskt och ett västnordiskt land, Sverige och Danmark, framträder i ett pågående forskningsprojekt om brottsskadeersättning vid Kriminologiska institutionen, Stockholms universitet (Rytterbro och Rönneling 2007). Den slående skillnaden i undersökningsmaterialet rör ersättning för kränkning. Medan endast 15 procent söker sådan ersättning i Danmark är det 90 procent i Sverige. Detta kan hänga samman med lagstiftningen - Sverige införde kränkning genom brott som egen skadetyp 2002. En sådan förklaring skjuter dock frågan om orsaken ett steg bakåt: varför infördes denna lagändring? Rör det sig om skillnader i kriminalpolitik och diskkurs i de båda länderna, och kan lagstiftningen i sin tur påverka inte bara möjligheten att få ersättning utan även upplevelsen av skadan?

\section{Alternativa sätt att hjälpa brottsoffret}

En skillnad mellan länderna visar sig också i att i Danmark betydligt större belopp tycks betalas ut än i Sverige. Vad detta beror på återstår att undersöka. Skillnaden pekar dock på vikten av att se brottskadeersättning i sin samhällskontext. Vilka andra sätt finns att kompensera offret eller minska hennes lidande? Vilken roll spelar allmänna och privata försäkringar, kostnader i samband med sjukhusbesök, förekomsten av brottsoffer- och kvinnojourer och så vidare? I en rapport om brottsoffers rätt till statlig ersättning (Königsson 2002) påpekas att de tidigare kommunistiska staterna i Europa sökt lösa kompensationen inom ramen för allmän hälsovård och socialförsäkringar. Detta kan ställas mot situationen i USA, där stora skadeståndsanspråk i samband med brott bland annat kan förstås mot bakgrund av ett betydligt mindre utbyggt allmänt trygghetssystem. Slutsatsen av detta är att en jämförelse av vad olika länder gör för brottsoffret måste sättas in i sitt sammanhang. Skillnader i mer socialpolitiska insatser för brottsoffret kan dock knappast förklara skillnader i brottsoffrets ställning i brottmålsprocessen i de nordiska länderna.

\section{Mänskliga rättigheter}

Aina Mee Ertzeid tar utifrån den norska modellen upp ett antal punkter för debatt. Bland skälen för att förbättra brottsoffrets ställning i brottmål framhåller hon den internationella utvecklingen. Att inte behöva utsättas för brott och särskilt att 
kvinnor inte ska behöva utsättas för våld formuleras nu av FN som en mänsklig rättighet. Häri ligger dock ett problem. Traditionellt förstår vi, som den norska kriminologen Heidi Mork Lomell framhållit, brott mot mänskliga rättigheter som något som staten utsätter medborgarna för (Lomell 2006). Nu blir staten garanten för brottsoffret, som har rättigheter, mot den misstänkte, vars rättigheter ska inskränkas. Staten kan i brottsoffrets namn komma att införa sådan kontroll som traditionellt uppfattats som brott mot mänskliga rättigheter. Exemplen är kanske tydligast i terroristbekämpningen men kan även hämtas från övervakningssamhällets utveckling i allmänhet. Den kontrollnivå vi fått idag skulle för en generation sedan uppfattats som helt oacceptabel ur ett människorättsperspektiv.

\section{Gärningsmannen konstituerar offret}

Aina Mee Ertzeid pekar på vikten av att justera kursen till brottoffrets fördel för att bevara tilltron till straffsystemet och för att omdefiniera vad det innebär att vara den kränkta i ett brottmål. Det är absolut viktigt att lagstiftaren och rättsväsendet på ett annat sätt än tidigare försöker förstå den skadelidandes situation och lyssnar på hennes eller hans önskemål. Kränkningen är dock inte alltid helt lätt att fastställa. Den är till del en konstruktion, en upplevelse som utvecklas i samspel med omgivningen. Den eventuella skillnaden i upplevd kräkning i Sverige och Danmark kan vara ett exempel på detta. Det idealiska offret kräver den idealiska gärningsmannen i Nils Christies (2001) termer. I dag tillskrivs gärningsmannen ett uppsåt och en ondska som han tidigare inte besatt. Förmildrande omständigheter eller förminskat ansvar på grund av till exempel berusning eller psykiska problem innebar också en möjlighet för brottsoffret att hävda att gärningsmannen egentligen inte ville förgripa sig och därmed hålla kränkningen ifrån sig. "No harm meant, no harm shed" - och offret behöver kanske inte känna sig lika kränkt. Detta är också en av idéerna bakom medling. A ena sidan ska gärningsmannen fås att förstå att han verkligen skadat och kränkt en konkret människa, å andra sidan kan gärningsmannens förklaring och ursäkt påverka den upplevda kränkningen.

\section{Vågskål och intressemotsättningar}

Aina Mee Ertzeid framhåller vikten av att brottsoffrets rättigheter inte spelas ut mot gärningsmannens och att ett vågskålsförfarande undviks. Detta är sympatiskt och bör vara vägledande för strävandena att förbättra brottsoffrets situation. Vi bör dock inte blunda för att en intressemotsättning kan uppstå. Om kravet ställs att en gärningsman ska fällas för att brottsoffret ska få upprättelse, kommer två principer i konflikt med varandra. Det bästa - och också allvarligaste - exemplet är här kanske våldtäkt. En friande dom, där ord står mot ord, blir en förlust för kvinnan som inte får upprättelse, och en fällande dom riskerar innebära att en oskyldig döms - något som tidigare ansetts vara det allvarligaste fel som kunde begås av en domstol. 
I dag drivs tydligt olika strategier i brottsofferfrågan. Medan några följer devisen "Hellre hjälpa brottsoffret än stjälpa gärningsmannen", har andra valt en linje där motsättningen mellan offer och gärningsman maximeras med ett vågskålsförfarande som konsekvens. Brottsoffrets eller anhörigas partstatus i rättsprocessen kan här även innebära ett nollsummespel. Det för Sverige kanske mest kända fallet rör Annika Österberg som sitter i fängelse i Kalifornien dömd för medhjälp till mord på en polisman. Vid frigivningsnämndens sammanträden sitter polismannens döttrar med och motsätter sig konsekvent frigivning, och Österberg har nu setat inne sex år längre än krigsförbrytaren Albert Speer som satt 20 år.

\section{Vad är en framgångsrik brottsofferpolitik?}

Sådana brott som innebär att män utövar våld mot kvinnor, som nu dominerar brottsofferdiskursen, ställer brottsofferfrågor och förslag till lösningar på sin spets. Aina Mee Ertzeid tog upp att i det norska utredningsbetänkandet från 2006 är det dessa brott som står i centrum. Detta innebär, liksom i den svenska brottsofferpolitiken, att andra brottsoffer till del kommer i skymundan. För att pröva vad som är bäst för brottsoffret - såväl i som utanför brottmålprocessen - är det viktigt att beakta skilda kategorier brottsoffer. Olika föreställningar om det typiska brottsoffret figurerar antagligen i både utredningar och i allmänhetens föreställningar. Samma lösningar kanske inte är bäst för alla brottsoffer.

Detta leder till frågan om vad som ska betraktas som en framgångsrik brottsofferpolitik. De förslag till reformer för att stärka brottsoffrets ställning i brottsmålsprocessen, som Aina Mee Ertzeid refererar och som framför allt berör ökad information, verkar i stort rimliga. Andra krav som alltmer förs fram är ökad uppklaring och fler dömda. Detta är inte alls ett lika givet kriterium på framgång. Det medför mycket stora kostnader för rättsväsendet, samtidigt som det är högst osäkert om risken att utsättas för brott minskar.

Det är här viktigt att framhålla att fortsatta strävanden att förbättra brottsoffrens situation baseras på faktisk kunskap om brottsoffrens önskningar, på olika gruppers behov och på vad forskning och erfarenhet visar. Brottsskadeersättning, till exempel, har hjälpt i en del fall men ibland också följts av ökad frustration (Elias 1986). Rätten att konfronteras med gärningsmannen har minskat rädslan och hatet, men möjligheten till isolering från honom genom besöksförbud eller överfallslarm har också värdesatts av brottsoffren (Brå 2007, Bakkesteig 2006). Rätttegång kan vara ett sätt att ge brottsoffret upprättelse men också vara ett olämpligt sätt för att reda ut komplicerade bekantskaps- och släktskapsrelationer. Det vidare och viktiga arbetet med att ge stöd till brottsoffret måste föras fördomsfritt och inte låsas av ideologier och annan förförståelse. 


\section{Litteratur:}

Bakkesteig, E. (2006), Mobil voldsalarm - en friere hverdag? PHS forskning 2006:1. Oslo: Politihögskolen.

Brå (2007), Besöksförbud. De berörda och deras erfarenheter. Stockholm: Brottsförebyggande rådet/Fritzes.

Christie, N. (1980), Nyklassisismens skjulte budskap, i Heckscher, S., Snare, A., Takala, H. \& Vestergaard, J. (red.), Straff och rättfärdighet - ny nordisk debatt. Stockholm: Norstedts.

Christie, N. (2001), Det idealiska offret, i Åkerström, M. \& Sahlin, I. (red.), Det motspänstiga offret. Lund: Studentlitteratur.

Elias, R. (1986), Victim assistance and criminal justice system, i Fattah, E. (red.), From Crime Policy to Victim Policy. London: Macmillan.

Justitiedepartementet (1993), Att renovera en förfallen kriminalpolitik. Stockholm: Regeringskansliets offsetcentral.

Königsson, M. (2002), Brottsoffers rätt till statlig ersättning. Examensarbete, 20 p. Lund: Juridiska fakulteten vid Lunds universitet.

Lomell, H.M. (2006), " - Menneskerettigheter er vel og bra, men for vem? Offret eller gjerningsmannen?" Nordisk Tidsskrift for Menneskerettigheter, vol. 24, nr 1, s. 59-73.

Rytterbro, L.-L. \& Rönneling, A. (2007), Brottsskadeersättning ur brottsofferperspektiv. En jämförelse av ansökningar i Sverige och Danmark. Papper presenterat vid Nordiska Samarbetsrådet för Kriminologi 48:e forskarseminarium, 1-3 juni 2006, Djurö, Sverige.

Stenborrre, E. (2003), Påföljdsbestämningen i Sverige och straffutmålningen $i$ Norge. Med en studie av rättsfall från Högsta domstolen och Höyesterett. Akademisk avhandling. Lund: Juridiska fakulteten vid Lunds universitet.

\section{Noter:}

1 Dag Victor framhöll under seminariet som alternativ förklaring att målsägande sedan tidigare haft en starkare ställning i Finland och Sverige än i de övriga nordiska länderna.

Adresse:

Kriminologiska institutionen

Stockholms universitet

SE -10691 Stockholm 